\title{
Chemogenomic and transcriptome analysis identifies mode of action of the chemosensitizing agent CTBT (7-chlorotetrazolo[5,1-c]benzo[1,2,4] triazine)
}

\author{
Monika Batova ${ }^{1,3}$, Vlasta Klobucnikova², Zuzana Oblasova ${ }^{1}$, Juraj Gregan ${ }^{3}$, Pavol Zahradnik ${ }^{4}$, Ivan Hapala²,
} Julius Subik ${ }^{1 *}$, Christoph Schüller ${ }^{5^{*}}$

\begin{abstract}
Background: CTBT (7-chlorotetrazolo [5,1-c]benzo[1,2,4]triazine) increases efficacy of commonly used antifungal agents by an unknown mechanism. It increases the susceptibility of Saccharomyces cerevisiae, Candida albicans and Candida glabrata cells to cycloheximide, 5-fluorocytosine and azole antimycotic drugs. Here we elucidate CTBT mode of action with a combination of systematic genetic and transcriptome analysis.

Results: To identify the cellular processes affected by CTBT, we screened the systematic haploid deletion mutant collection for CTBT sensitive mutants. We identified 169 hypersensitive deletion mutants. The deleted genes encode proteins mainly involved in mitochondrial functions, DNA repair, transcription and chromatin remodeling, and oxidative stress response. We found that the susceptibility of yeast cells to CTBT depends on molecular oxygen. Transcriptome analysis of the immediate early response to CTBT revealed rapid induction of oxidant and stress response defense genes. Many of these genes depend on the transcription factors Yap1 and Cin5. Yap1 accumulates rapidly in the nucleus in CTBT treated cells suggesting acute oxidative stress. Moreover, molecular calculations supported a superoxide generating activity of CTBT. Superoxide production in vivo by CTBT was found associated to mitochondria as indicated by oxidation of MitoSOX Red.
\end{abstract}

Conclusion: We conclude that CTBT causes intracellular superoxide production and oxidative stress in fungal cells and is thus enhancing antimycotic drug effects by a secondary stress.

\section{Background}

Fugal pathogens pose a serious threat to immunocompromised persons. Despite many antifungal agents interfering with metabolism and growth of fungal cells a limited number of compounds are being used for treatment of mycotic diseases caused by human pathogenic fungal species. Over the past two decades, the number of invasive fungal infections has increased in the clinical setting. Candida $s p$. is the fourth most common pathogen identified, and other pathogens such as Cryptococcus sp., Aspergillus sp., and Fusarium sp., have a high

\footnotetext{
* Correspondence: subik@fns.uniba.sk; Christoph.schueller@univie.ac.at 'Comenius University in Bratislava, Department of Microbiology and Virology, 84215 Bratislava, Slovak Republic

${ }^{5}$ University of Vienna, Max F Perutz Laboratories, Department of Biochemistry and Cell Biology, A-1030 Vienna, Austria
}

morbidity and mortality. In addition, the incidence of mycoses caused by opportunistic fungi is rising [1]. CTBT, 7-chlorotetrazolo [5,1-c]benzo[1,2,4] triazine, has antifungal activity and enhances the efficacy of other antifungals with different targets such as cycloheximide, fluconazole or 5-fluorocytosine [2]. The molecular mechanism of CTBT action has not yet been resolved.

Currently used antifungals belong to three major classes of agents: azoles, polyenes, and echinocandines [3]. These compounds target ergosterol biosynthesis, membrane functions and cell wall biosynthesis. Additionally, other currently applied compounds are the pyrimidine, 5-fluorocytosine (5-FC), which acts by inhibiting RNA and DNA synthesis [4] and ciclopiroxolamine which seems to induce oxidative stress and iron deprivation [5]. The intrinsic resistance of human fungal 
pathogens to these substances is different. Echinocandins are effective in Candida prevention and offer a greater spectrum of activity across the various Candida species, including also C. krusei and C. glabrata, which are not reliably covered by azoles e.g. fluconazole [6].

Fungal drug resistance mechanisms involve decreased drug uptake, increased drug export, overexpression or structural modification of the drug target protein $[7,8]$. Reversal of antifungal drug effectiveness in yeast cells mediated by efflux has been reported for a variety of substances targeting different molecular processes. These are for example the immunosuppressive agents FK506 and cyclosporine [9-13]. To overcome drug resistance of human fungal pathogens, new antifungals with novel cellular targets [14] and multidrug resistance reversal agents rendering drug resistant strains sensitive to commercially used antifungals are being developed $[15,16]$ but have not surfaced as yet. Studies evaluating combinations of antifungals have shown synergistic and additive activity. However, caution is required, because some antifungal combinations have demonstrated antagonistic activity. Controlled clinical trials are still necessary to explore the various efficacious antifungal combinations [17]. Since the common antifungals are mainly targeting membrane and cell wall components, efficient combination therapy might be reached by involving substances with an alternative mode of action.

The site and mode of CTBT action have not yet been resolved. CTBT displayed a weak antifungal activity which was unaffected by deletion of the PDR 1 and $P D R 3$ genes encoding the main transcription activators involved in the control of multidrug resistance in Saccharomyces cerevisiae $[18,19]$. Yeast cells grown in its presence had altered sterol composition and were more sensitive to this compound in the yap $1 \Delta$ genetic background [2]. Here we report insights gained for the mode of CTBT action by systematic identification of yeast genes required for resistance to CTBT in combination with transcriptome analysis. We will show that CTBT causes an unexpected dramatic response to oxidative stress including damage to mitochondria and genomic DNA. These results provide a model for CTBT action and indicate that its synergic effect with commonly used antifungal drugs is due to the combination of oxidative and other stresses.

\section{Results \\ CTBT action depends on molecular oxygen and is connected by mitochondrial functions}

CTBT has been shown to display cytotoxic activity and the ability to enhance the activity of several antifungal agents at sub-inhibitory concentrations [2]. In disk diffusion assay on YPD medium using the $S$. cerevisiae BY4741 wild type and its rho mutant strains CTBT induced the formation of clear growth inhibition zones that were surrounded by outer inhibition zones corresponding to reduced yeast growth (Figure 1A, B). Growth inhibition zones of respiring cells growing on YPGE medium containing glycerol plus ethanol were significantly larger compared to those with fermenting cells on YPD. This suggested that CTBT disrupted mitochondrial functions (Figure 1C). Essentially the same results were obtained with the BY4742 and FY1678-28C wild type strains (data not shown). On the other hand, $S$. cerevisiae yeast cells grown anaerobically were found to be insensitive to CTBT. As expected for qualitative anaerobicity of our experimental setup, both strains failed to grow anaerobically without ergosterol and unsaturated fatty acids. No inhibition zones were observed when cells of the BY4741 and BY4742 wild
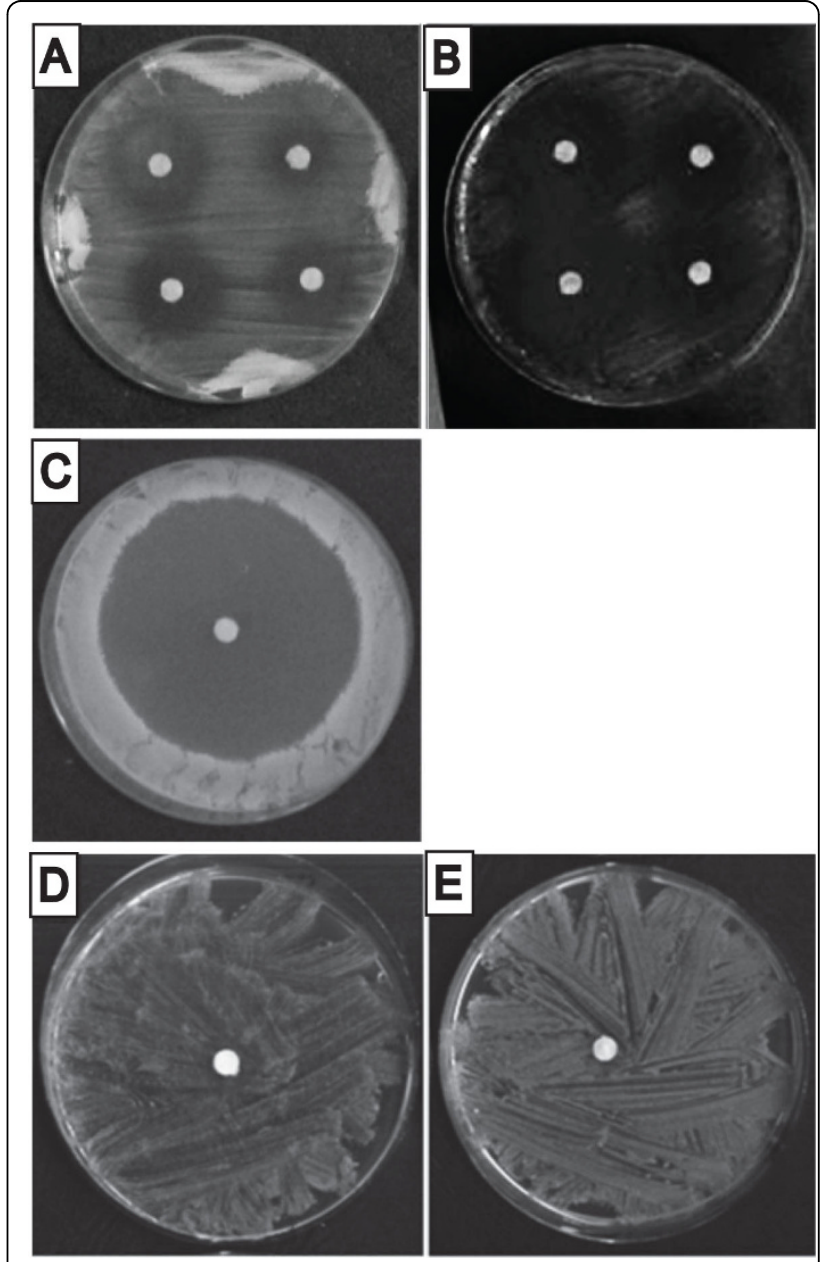

Figure 1 CTBT induced growth inhibition zones on complex media. S. cerevisiae BY4741 wild type on YPD. (A), BY4741 rhomutant on YPD (B), BY4741 on YPGE (C), BY4741 (D) and BY4742 (E) grown anaerobically on YPD supplemented with ergosterol plus Tween 80. Amounts of CTBT per disk were: $5 \mu \mathrm{g}$ (left part in A and B), $10 \mu \mathrm{g}$ (right part in $\mathrm{A}, \mathrm{B}$ and $\mathrm{C}-\mathrm{E}$ ). 
type strains were grown in the absence of molecular oxygen on YPD medium supplemented with ergosterol and unsaturated fatty acids (Figure 1D, E). These results clearly indicate that mitochondrial functions and molecular oxygen are involved in the CTBT susceptibility in yeast cells.

\section{Identification of yeast deletion mutants with increased CTBT susceptibility}

To gain more insight into CTBT action we systematically identified mutants with altered sensitivity. We screened the $S$. cerevisiae haploid deletion mutant collection for altered growth in the presence of CTBT. The wild type strain BY4741 from which the EUROSCARF collection has been derived was unable to grow on YPD medium supplemented with $6 \mu \mathrm{g} / \mathrm{ml}$ of CTBT. Therefore, the hypersensitive mutant strains were identified on YPD media containing 2 and $4 \mu \mathrm{g} / \mathrm{ml}$ of CTBT. Using pin replicator, cells of each mutant strain grown in YPD medium containing G418 sulphate were replicated as quadruplets to CTBT containing medium and to YPD control plate. After 6 days of growth the mutant strains sensitive to 2 or $4 \mu \mathrm{g} / \mathrm{ml}$ of CTBT were identified, collected and their sensitivity to CTBT confirmed in independent assays. This screen of the 4700 haploid gene deletion mutants was carried out once and resulted in the isolation of 169 CTBT hypersensitive mutant strains (Additional file 1).

Significantly, some molecular complexes or biochemical pathways were represented by more than one mutant (Table 1). In order to assign cellular functions contributing to CTBT tolerance we searched for enriched gene ontology (GO) categories according to the SGD GO-Termfinder. The most prominent GO terms associated to the genes required for CTBT tolerance were functions related to mitochondria, transcription, DNA repair, and stress response (Table 2).

The largest group of strains hypersensitive to CTBT contained deletions in genes for mitochondrial biogenesis and functions, including DNA replication (MIP1), mRNA processing (MRS1), protein synthesis and processing (AFG3, DIA4, MRPL49, MRPS35, MSY1, MTG1, OCT1, PCP1, RML2, RSM19, TUF1), respiration (CYT1), ATP synthesis (ATP1, ATP11, ATP12, ATP18), Fe/S protein biosynthesis (ISA1, ISA2), superoxide dismutation (SOD1, SOD2) and others.

In the second largest group were mutants in genes involved in gene expression thus hinting at an acute transcriptional response to CTBT. Identified genes are involved in chromatin remodeling (ARP5, HOS2, HTZ1, RSC1, SGF73, SNF2, SWI3, SWI4, YAF9), transcription (CTK1, MED2, ROX3, RRN10, RTF1, SPT4, SPT20, $S R B 5, T A F 14, T H O 2)$ or encode transcription factors involved in oxidative stress response (YAP1, YAP7, SKN7) and lipid biosynthesis (OPI1).

We identified at least 11 CTBT sensitive strains containing deletion in DNA repair genes, including those involved in homologous recombination and repair (MMS1, MMS4, RAD50, RAD51, RAD52, RAD57), post replication repair $(R A D 6, R A D 18)$, double strand break repair (MRE11, XRS2), excision repair (MET18) and others. Importantly, deletion of genes encoding functions in lipid metabolism also impaired CTBT tolerance. These are involved in ergosterol (DAP1, ERG2, ERG3,

Table 1 Functions of selected genes deleted in CTBT sensitive mutant strains

\begin{tabular}{|c|c|}
\hline Function & Gene (ORF) name \\
\hline Mitochondrial functions & $\begin{array}{l}\text { ADH1, AFG3, ATP1, ATP11, ATP12, ATP18, CIT1, CYT1, DIA4, IMP1, ISA1, ISA2, MAS37, MDM32, MDM38, MGM1, MIP1, } \\
\text { MRPL49, MRPS35, MRS1, MSY1, MTG1, OCT1, PCP1, PDC1, PHB1, RML2, RSM19, SOD1, SOD2, TUF1, YDR115W, YGLO85W }\end{array}$ \\
\hline $\begin{array}{l}\text { Chromatin remodeling and } \\
\text { transcription }\end{array}$ & $\begin{array}{l}\text { ARP5, CDC73, CTK1, HOS2, HPR1, IES6, MED2, MGA2, OPI1, PGD1, RRN10, RME1, ROX3, RSC1, RTF1, RTT109, SGF73, SKN7, } \\
\text { SNF2, SPT4, SPT20, SRB5, STP1, SWI3, SWI4, TAF14, THO2, UME6, YAF9, YAP1, YAP7 }\end{array}$ \\
\hline DNA repair & MET18, MMS1, MMS4, MRE11, RAD6, RAD18, RAD50, RAD51, RAD54, RAD57, XRS2 \\
\hline Lipid metabolism & AKR1, CHO1, CHO2, DAP1, ERG2, ERG3, ERG6, ERG24, MGA2, OPI1 \\
\hline $\begin{array}{l}\text { Stress response and signal } \\
\text { transduction }\end{array}$ & ASC1, BCK1, CCS1, CTR1, CYS3, NBP2, REG1, SKN7, SNF1, SOD1, SOD2, YAP1, YAP7 \\
\hline Vacuolar functions & AVT4, CWH36, KCS1, TFP1, TFP3, VMA4, VMA21, VMA22 \\
\hline $\begin{array}{l}\text { Protein sorting and } \\
\text { degradation }\end{array}$ & DIA2, MAP1, PRE9, RAD6, VPS15, VPS20, VPS34 \\
\hline Amino acid metabolism & CYS3, ILV1, PRO2, TRP2, TRP3, TRP5 \\
\hline Transport & AVT4, CTR1, MUP1, TAT1 \\
\hline Mannosyl transferases & ANP1, OCH1 \\
\hline Pentose phosphate pathway & GND1, RPE1 \\
\hline Ungrouped & $\begin{array}{l}\text { ARD1, BEM1, BIM1, BUB3, BUD25, BUD27, BUR2, CDC50, CIK1, CSM1, CTF18, ENV6, FYV10, GEP4, GET2, HTZ1, KRE28, } \\
\text { MTC5, NAT1, NAT3, NCE101, NPT1, NRP1, NUP133, ORM2, PHO85, RAl1, RCY1, REF2, RG11, RNR4, RPL1B, RPL2A, RPL42B, } \\
\text { RTC1, SBH1, YIM2 }\end{array}$ \\
\hline Unknown functions & YDR049W, YDR114C, YHR045W, YNR065C, YOR305W \\
\hline
\end{tabular}


Table 2 GO-terms significantly enriched in the 169 genes required for CTBT tolerance (SGD GO-termFinder).

\begin{tabular}{lcc}
\hline GO_term & Frequency & P-value \\
\hline response to stimulus & $27.2 \%$ & $2.28 \mathrm{E}-06$ \\
transcription & $23.1 \%$ & $2.73 \mathrm{E}-06$ \\
response to stress & $20.1 \%$ & $6.35 \mathrm{E}-05$ \\
DNA repair & $10.7 \%$ & 0.00096 \\
organelle organization (mitochondrion) & $29.6 \%$ & 0.0033 \\
\hline
\end{tabular}

ERG6, ERG24), fatty acid (MGA2) and phospholipid biosynthesis (CHO1, CHO2, OPI1). Along with superoxide dismutase encoding genes, SOD1 and SOD2, which have a primary role in superoxide radical detoxification, other genes involved in oxidative stress response were also identified. The CCS1 gene encodes the specific copper chaperone delivering the copper to Sod1. The CTR1 gene is coding for a high affinity copper transporter of the plasma membrane. The transcription factors $Y A P 1$, $Y A P 7$ and SKN7 are involved in transcriptional regulation of oxidative stress response genes including $S O D 1$, $S O D 2$ and others. Additional functions required for CTBT tolerance involve vacuolar metabolism, protein sorting, amino acid metabolisms and others (Table 1). Importantly, many genes with CTBT defense functions overlap with those involved in menadion, hydrogen peroxide and arsenic stress tolerance [20-23].

The results of phenotypic profiling and the oxygen dependence of CTBT action, led us to the suggestion that CTBT induces reactive oxygen species in yeast cells.

Transcriptional profile analysis of CTBT treated yeast cells Profiles of transcriptional responses can be used to identify cellular defense processes. We therefore investigated the immediate response of wild type BY4741 cells treated with CTBT. We used a dose $1 / 3^{\text {rd }}$ of the minimal inhibitory concentration $(6 \mu \mathrm{g} / \mathrm{ml}) 2 \mu \mathrm{g} / \mathrm{ml}$ in a time curse of 5, 10, 20 and $40 \mathrm{~min}$ in liquid medium. Expression data were collected from duplicate arrays. We identified 314 genes induced in at least one time point by more than 2 fold and 186 genes repressed more than 2 fold (Additional file 2 and 3). Repressed genes comprised many genes with functions in protein biosynthesis (Table 3). This has been observed previously in transcript profiles from cells treated with various other compounds or exposed to stressful conditions [24] and correlates frequently with repression of Sfp1 function $[25,26]$. Most ribosomal protein genes were repressed to about half of the level of exponentially growing cells.

The induction kinetics had an early and a delayed transcriptional wave. Notably, the genes with eminent antioxidant functions were induced most rapidly. Many induced genes were linked to mitochondrial functions and oxidative stress response (Figure 2A, S1). We
Table 3 GO-terms significantly enriched in the $500>2$ fold induced or repressed genes (SGD GO-termFinder).

\begin{tabular}{lcc}
\hline GO_term & Frequency & P-value \\
\hline preribosome & $8.2 \%$ & $1.68 \mathrm{E}-14$ \\
nucleus & $37.2 \%$ & 0.00195 \\
mitochondrion & $61.0 \%$ & 0.00546 \\
RNA polymerase complex & $2.0 \%$ & 0.0093 \\
response to oxidative stress & $5.40 \%$ & $2.39 \mathrm{E}-09$ \\
monosaccharide catabolic process & $3.40 \%$ & $1.14 \mathrm{E}-05$ \\
response to chemical stimulus & $11.40 \%$ & $1.31 \mathrm{E}-05$ \\
cell redox homeostasis & $1.60 \%$ & $6.20 \mathrm{E}-05$ \\
alcohol metabolic process & $6.60 \%$ & 0.0012 \\
\hline
\end{tabular}

further predicted the possible transcription factors involved. T-profiler based analysis revealed that among the induced genes some transcription factor binding sites were highly enriched $[27,28]$. These were the general stress transcription factors Msn2 and Msn4, but more prominently the oxidative stress response factors Yap1, Skn7, Yap7, and Cin5/Yap4 (Table 4). Especially many Yap1 and Skn7 targeted genes were evident in the immediate early response genes. Moreover, a number of Cin5/Yap4 target genes were found to establish a second non-overlapping oxidative stress regulon (Figure $2 \mathrm{~B}$ ). Among the CTBT repressed genes we noticed a number of genes involved in the ergosterol biosynthesis (Figure $2 \mathrm{C}$ ) and the target of azoles antifungals, the enzyme lanosterol 14-alpha-demethylase Erg11p. To demonstrate a general effect on these genes we show the expression profiles of the genes associated to the GOterm lipid biosynthesis (Figure 2C).

Next we analyzed the connection between transcript and phenotype profiles (Figure 3A). Generally, phenotypic display data do not have large overlaps with transcript profile data. This is due to the fact that pathways activate many target genes in parallel with sometime redundant functions. However, in some cases the overlap is informative since it points to exceptionally important nodes of stress resistance [29]. Here we found a small number of genes both required for tolerance and significantly induced. They encode proteins required for several different mitochondrial functions: ISA2, a protein required for maturation of mitochondrial and cytosolic Fe/S proteins, ATP1, the alpha subunit of the $\mathrm{H}^{+}$ATPase, SOD1 the cytosolic superoxide dismutase, CCS1 the copper chaperone for Sod1p and SOD2, the mitochondrial superoxide dismutase. This overlap points to an essential response to CTBT originating from or localized to mitochondria. Furthermore, the transcription factors Srb5, Yap1 and Yap7 are induced also at the level of transcription (Figure 3A). Comparison of 169 genes required for resistance to CTBT, and 689 required for hydrogen peroxide, menadione, mefloquine, and 

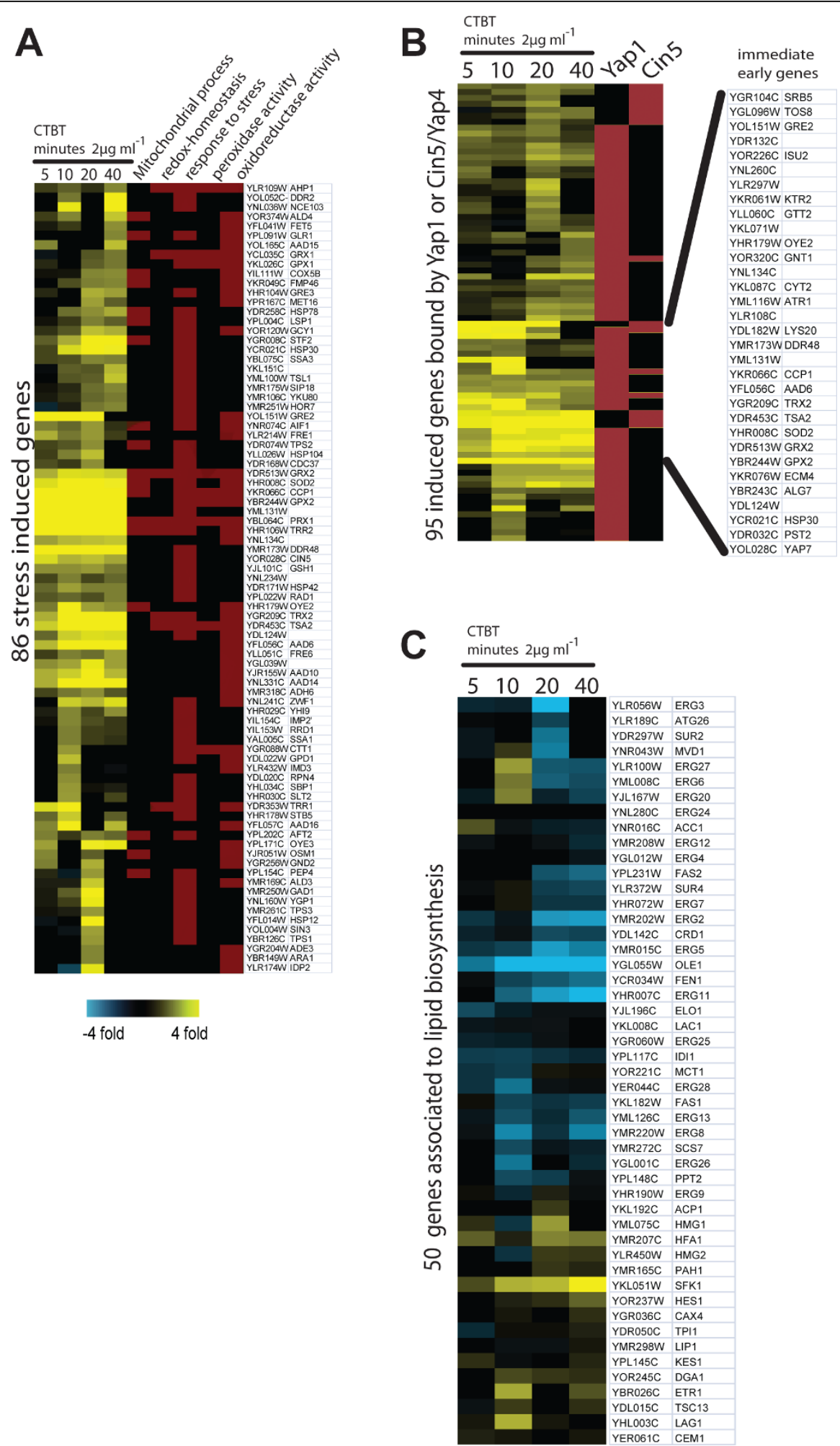

Figure 2 Transcript profiles of CTBT treated yeast cells. Exponentially growing cells were treated with $2 \mu \mathrm{g} \mathrm{ml}{ }^{-1} \mathrm{CTBT}_{\text {for the indicated times }}$ and microarrays of treated versus untreated cells were done in triplicates. Expression data of genes associated to the GO-term stress response (A), genes regulated and targeted by Yap1 and Cin5 according to Harbison et al., 2004 [27] (B), and the GO-term lipid biosynthetic process (C) were clustered. Enriched GO-terms associated to the respective genes are indicated as colored bars. The full expression dataset is available as supplementary file. 
Table 4 Transcription factor binding sites enriched in CTBT regulated genes.

\begin{tabular}{llcccc}
\hline Motif & Name & t-value & E-value & Mean & ORFs \\
\hline TTASTAA & YAP1 & 4.91 & $1.30 \mathrm{E}-04$ & 0.713 & 82 \\
AGGGG & MSN2-4 & 4.72 & $3.40 \mathrm{E}-04$ & 0.611 & 120 \\
MTTAYRTAAK & CIN5 & 4.46 & $1.20 \mathrm{E}-03$ & 1.235 & 17 \\
CCCCT & MSN2-4 & 4 & $9.20 \mathrm{E}-03$ & 0.57 & 118 \\
CGATGAG & PAC & -6.48 & $1.30 \mathrm{E}-08$ & -0.344 & 58 \\
AAAATT & rRPE & -6.57 & $7.30 \mathrm{E}-09$ & -0.039 & 156 \\
\hline
\end{tabular}

ibuprophen reistance [22] showed a significant overlap (86 genes, cumulative hypergeometric probability $\mathrm{P}<10^{-30}$; Figure $\left.3 \mathrm{~B}, \mathrm{C}\right)$. We could not detect a significant bias of genes required for resistance to hydrogen peroxide, menadione, mefloquine, and ibuprophen in our dataset, indicating induction of general oxidative stress by CTBT.

Yap1 accumulates rapidly in the nucleus in cells exposed to oxidative stress [30]. We followed the intracellular distribution of Yap1-GFP construct and found a similar rapid accumulation of Yap1 in both CTBT and hydrogen peroxide stressed cells (Figure 4A, B). Taken together the transcript profiling data support the phenotypic display by pointing to an immediate oxidative stress response and furthermore to an important protective function of superoxide scavenging and mitochondrial activity.

\section{Mitochondrial superoxide production and petite mutant formation in CTBT treated yeast cells}

$S$. cerevisiae mutant strains deleted in the SOD 1 or $S O D 2$ genes were found to be the most sensitive to CTBT. The minimal inhibitory concentrations of CTBT determined by broth dilution method for the $\operatorname{sod} 1 \Delta$ and sod $2 \Delta$ mutants $(0.5 \mu \mathrm{g} / \mathrm{ml})$ were 10 -times reduced compared to the wild type strain. Thus, we suspected that CTBT induces superoxide formation. To determine this directly, MitoSOX Red was used to assess superoxide radical production in live cells. This dye is selectively targeted to the mitochondria where it is selectively oxidized by superoxide and exhibits red fluorescence upon binding to nucleic acids [31]. As shown in Figure 5A, a large fraction of wild type cells grown for $12 \mathrm{~h}$ in YPGal medium in the presence of sub-inhibitory concentrations of CTBT accumulated the dye and fluoresced intensively red, compared with control cells grown in the absence of CTBT. Analysis of individual cells under a fluorescence microscope revealed cells with mitochondrial fluorescence. In addition, a small fraction of cells showed red brilliant fluorescence, which may represent severely damaged or dead cells [32] (Figure 5B). A high percentage of cells exhibiting mitochondrial fluorescence was also observed in the population of the $\operatorname{sod} 2 \Delta$ mutant strain treated with a 10-times lower concentration of CTBT. In the genetic background of the S. cerevisiae EG103 strain the sod1A mutant cells were significantly more sensitive to CTBT compared with the $\operatorname{sod} 2 \Delta$ cells. These results demonstrate that CTBT induces an increased production of superoxide that may disturb many cellular functions by damaging nucleic acids, oxidizing proteins and causing lipid peroxidation. In fact, when the sod $2 \Delta$ mutant cells were grown for 24 $\mathrm{h}$ in YPD medium containing a sub-inhibitory concentration of CTBT the respiration deficient petite mutants were induced in high frequency indicating the damage to mtDNA induced by CTBT (Table 5). Both the CTBT treatment and the absence of Sod1 or Sod2 result in increased ROS formation [33,34]. It was also possible that CTBT mediated inactivation of Sod1p and/or Sod2p might contribute partly to the observed ROS formation. To assess the role of superoxide dismutases, the isogenic series of the $\operatorname{sod} 1 \Delta, \operatorname{sod} 2 \Delta$ and $\operatorname{sod} 1 \Delta \operatorname{sod} 2 \Delta$ mutant strains derived from the $S$. cerevisiae EG103 wild type strain were used in zone inhibition assay with CTBT ( $5 \mu \mathrm{g}$ per disk) on YPD. We observed that sensitivity of the $\operatorname{sod} 1 \Delta \operatorname{sod} 2 \Delta$ double mutant cells was slightly higher compared to the sod1 $1 \Delta$ mutant (Figure $5 \mathrm{C})$. We conclude that enhanced ROS production by CTBT treatment is counteracted by both superoxide dismutases.

\section{Theoretical treatment of CTBT activity}

In order to get more insight into the mechanism of CTBT induced superoxide generation we used the standard computational protocol to perform quantum chemical calculations of 6 tetrazolo- and triazolobenzotriazines described previously [2]. To compare the important structural parameters and their influence on the biological activity, the unsubstituted $[1,2,4]$ triazolo $[3,4, \mathrm{c}]$ benzo[ $[1,2,4]$ triazine (compound 3 ) was added to the original series. Four parameters that could be related to biological activity of compounds were chosen. $\log \mathrm{P}$ models the transport of molecules in biological systems, $\mu$ is the dipole moment of isolated molecule in Debye units, HOMO (Highest Occupied Orbital) and LUMO (Lowest Unoccupied Orbital) stand for energy of frontier orbitals in $\mathrm{eV}$ units.

As shown in Figure 6, CTBT is predicted to yield the lowest values of dipole moment, HOMO orbital energy and mainly very low value of LUMO orbital energy compared with another compounds under study. The value of LUMO energy appears to be the most important calculated parameter for possible explanation of CTBT activity related to its antifungal effect expressed as the diameter of the growth inhibition zone (DGIZ). If one electron reduction would be assumed as the first step in CTBT mediated superoxide production, the low 
A

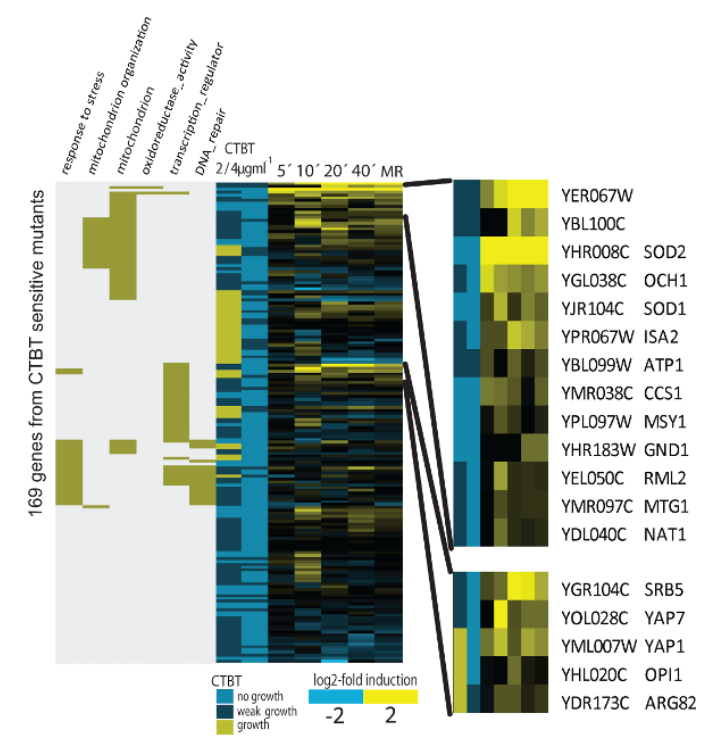

B

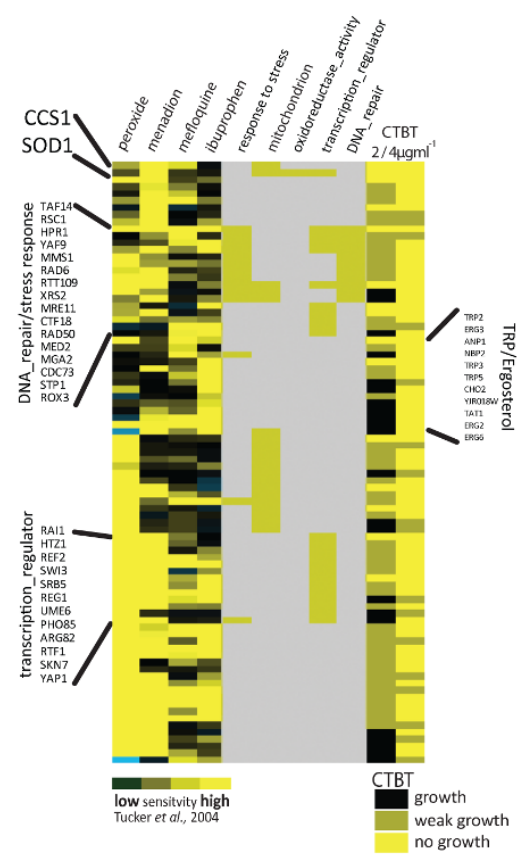

C

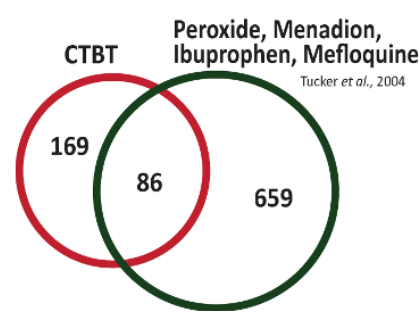

Figure 3 Comparison of phenotypic and expression profiles. A) Enriched GO-terms in the 169 genes deleted in the CTBT sensitive mutant strains are indicated in the left panels. Sensitivity levels to 2 and $4 \mu \mathrm{g} / \mathrm{ml} \mathrm{CTBT}$ are colour coded as indicated. GO, sensitivity and expression data were hierarchical clustered. Genes belonging to two clusters which are highly expressed and the corresponding mutants highly sensitivity are enlarged and indicate involvement of superoxide dismutases and oxidative stress specific transcription factors. B) Comparison of CTBT sensitive strains to hydrogen peroxide, menadion, mefloquine and ibuprophen sensitive strains. Fitness values (log2 transformed) from [22] were clustered with CTBT sensitivity values (2 very sensitive, 1 sensitive, 0 insensitive). To visualize all genes included in these graphs in TreeView, the raw data are available as supplementary files. C) A Venn diagram shows the overlap between CTBT and datasets from Tucker and Fields [22]. 
A

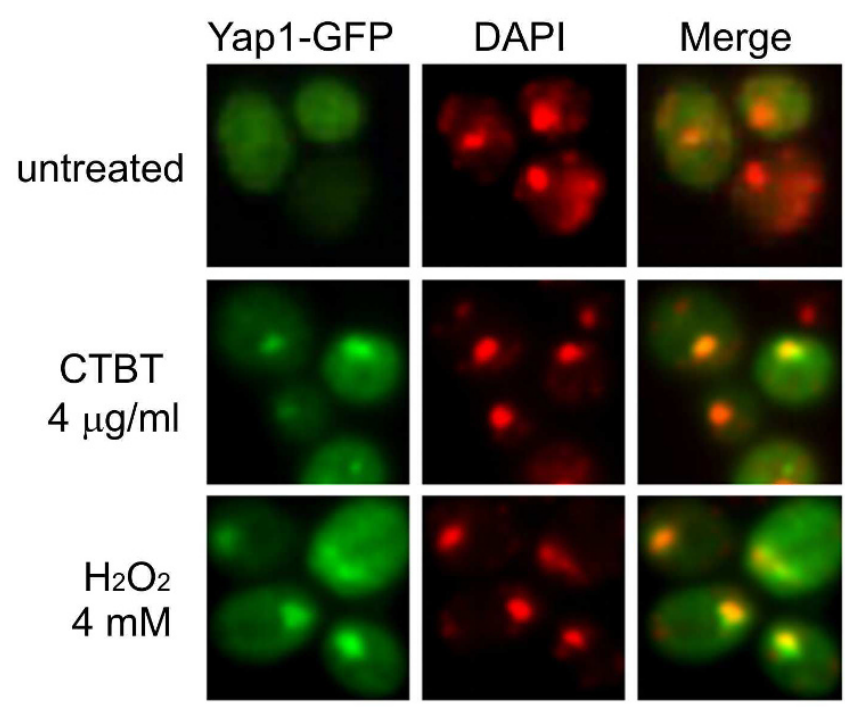

B
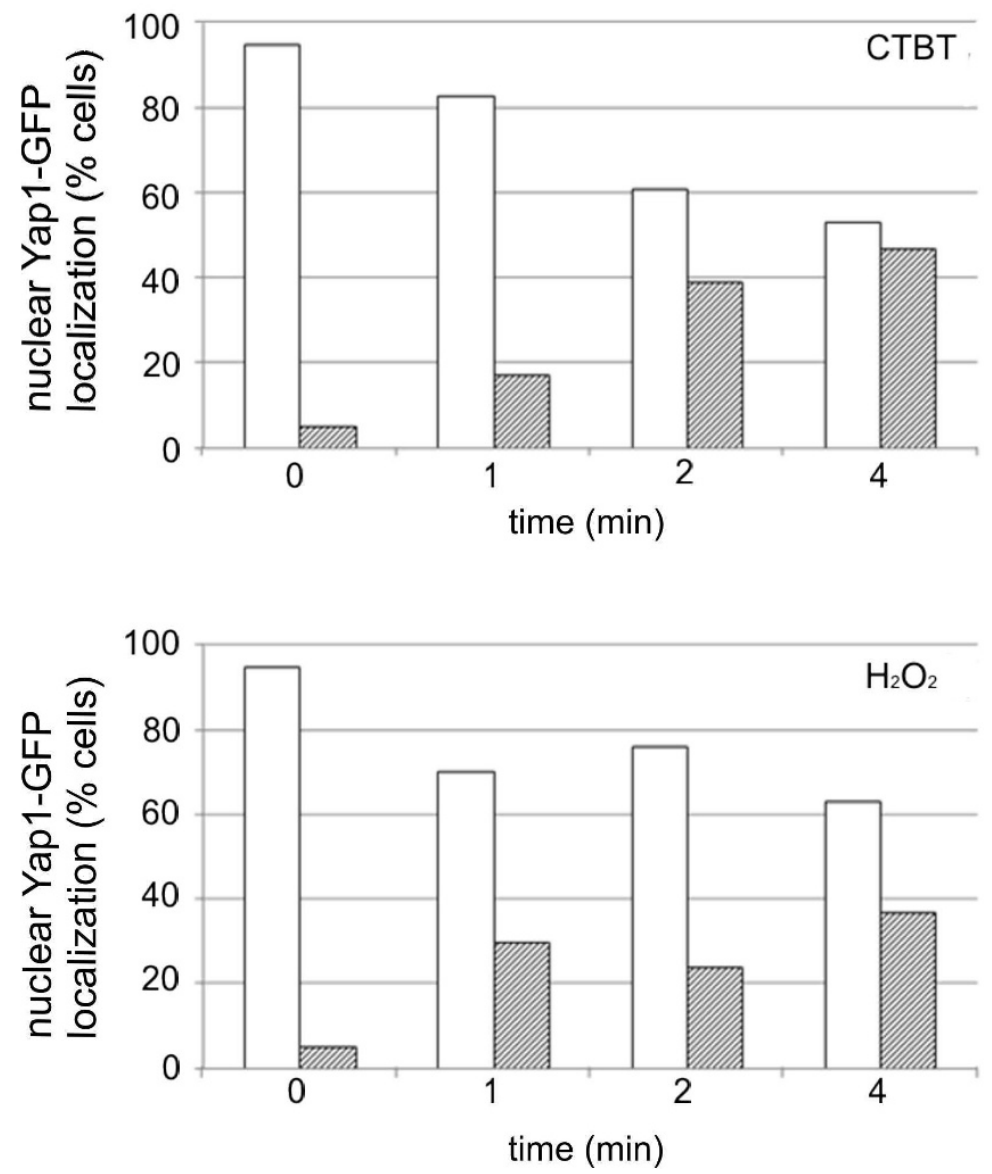

Figure 4 Analysis of Yap1-GFP localization in CTBT-treated cells. Exponentially growing yeast cells (EG103) were exposed for indicated time to CTBT $(4 \mu \mathrm{g} / \mathrm{ml})$ and hydrogen peroxide $(4 \mathrm{mM})$ as a positive control. Nuclear localization of Yap1-GFP was verified by co-localization with nuclei stained with DAPI $(2 \mu \mathrm{g} / \mathrm{ml})$ (A). For each sample, at least 100 cells were scored for subcellular localization of Yap1-GFP. Open bars represent cells with cytoplasmic Yap1-GFP, hatched bars represent cells with nuclear Yap1-GFP (B). Data are presented as the average of the two independent experiments. 

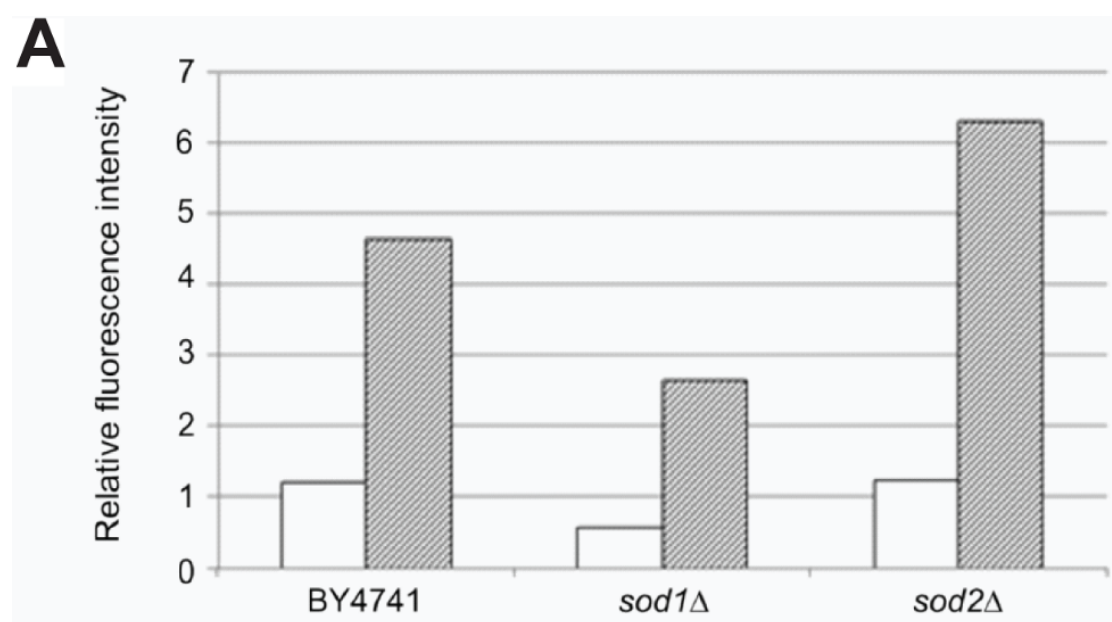

B

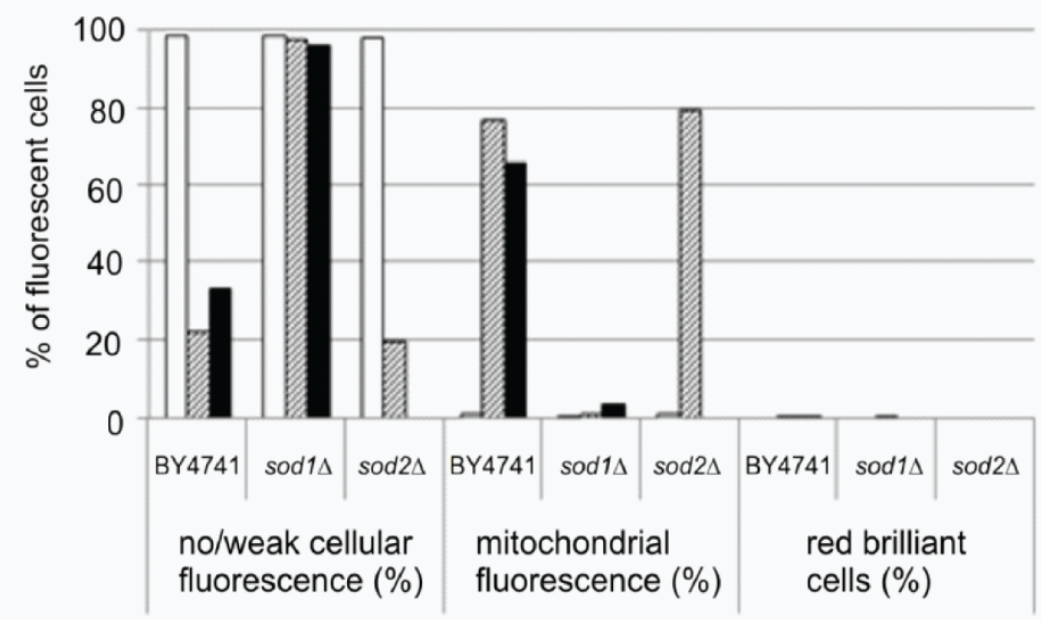

C
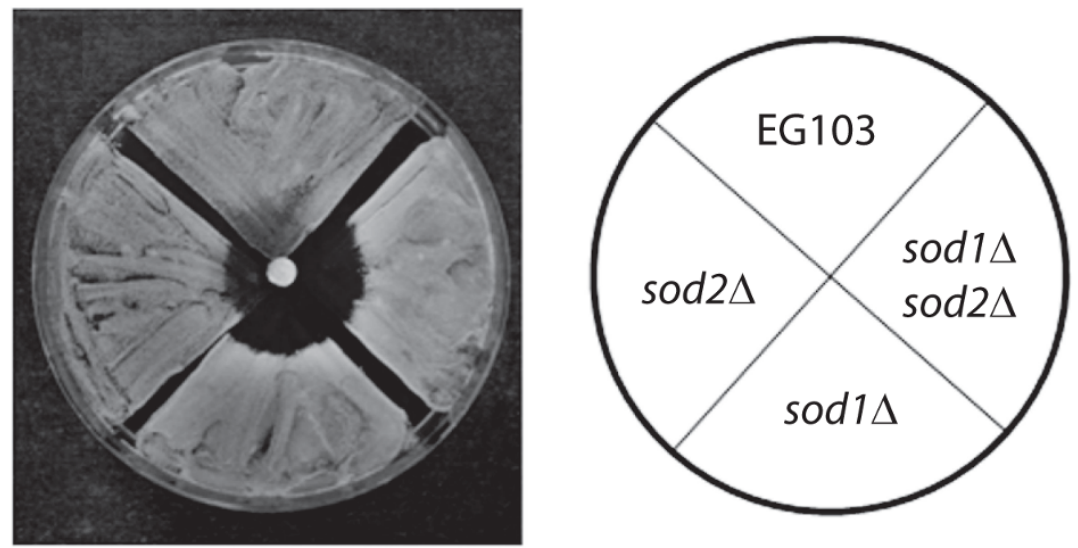

Figure 5 Superoxide production and growth inhibition in CTBT treated cells. Fluorescence of oxidized MitoSOX Red was determined using fluorescence spectrometry (A) and fluorescence microscopy (B). The values represent the means of 3 independent experiments. Open bars represent cells grown without CTBT. Wild-type cells (BY4741) were grown in the presence of $2 \mu \mathrm{g} / \mathrm{ml}$ (hatched bars) and $4 \mu \mathrm{g} / \mathrm{ml}$ (filled bars) CTBT. sod $1 \Delta$ mutant cells were grown in the presence of $0.25 \mu \mathrm{g} / \mathrm{ml}$ (hatched bars) and $0.4 \mu \mathrm{g} / \mathrm{ml}$ (filled bars) CTBT. sod $2 \Delta$ mutant cells were grown in the presence of $0.25 \mu \mathrm{g} / \mathrm{ml}$ CTBT (hatched bars). (C) Growth inhibition zones of CTBT in mutant strains lacking the indicated superoxide dismutase genes was scored after 5 days incubation. 
Table 5 Respiration deficient mutant formation in yeast cultures grown for $24 \mathrm{~h}$ in YPD medium containing indicated concentrations of CTBT

\begin{tabular}{lcc}
\hline Strain & CTBT $(\boldsymbol{\mu} \mathbf{g} / \mathbf{m l})$ & Petite mutants $(\%)$ \\
\hline BY4741 & 0 & 0.2 \\
& 2 & 0.2 \\
& 4 & 0.5 \\
sod1 $\Delta$ & 0 & 0.1 \\
& 0.25 & 0.6 \\
sod2 $\Delta$ & 0 & \\
& 0.25 & 0.1 \\
\hline
\end{tabular}

The results are means of two experiments.

value of LUMO energy makes the electron transfer into LUMO of CTBT leading to CTBT radical easily possible.

In the chemical structure of studied molecules there are two structural characteristics that decrease significantly the LUMO-energy i.e. chlorine atom and tetrazolo ring that both are incorporated into CTBT. Consequently, CTBT appears as the main candidate for redox cycling and superoxide generation among the studied molecules. These calculations and the genetic data show that CTBT has a capacity to generate superoxide radicals with reducing equivalents possible derived from the respiratory chain.

\section{Discussion}

In this study we show that CTBT, a compound enhancing the antifungal activity of several drugs [2], generates superoxide and other reactive oxygen species (ROS) and induces massive oxidative stress in yeast cells which enhances the antifungal activity of several unrelated drugs.

Five lines of evidence suggest that CTBT produces oxidative stress via generation of superoxide. First, CTBT toxicity required molecular oxygen. Second, it has predicted molecular properties of a molecule capable of redox cycling. Third, we detected oxidative stress using the two in vivo reporters MitoSOX Red and Yap1GFP. Fourth, genetic evidence was provided by the isolation of characteristic mutants with defects in oxidative stress scavenging functions. Fifth, transcription profiling showed activation of regulons associated with oxidative stress response. CTBT activity was strictly dependent on the presence of molecular oxygen because no inhibition

(1)

Figure 6 Structure, calculated theoretical data and growth inhibition caused by CTBT and related compounds. Log P: partition coefficient in octanol-water system; $\mu$ : dipole moment of isolated molecule; HOMO: energy of the Highest Occupied Molecular Orbital; LUMO: energy of the Lowest Unoccupied Molecular Orbital. DGIZ: diameter of growth inhibition in zone inhibition assay on solid medium caused by CTBT [5 $\mu \mathrm{g}$ added to paper disk (diameter of $6 \mathrm{~mm}$ )]. CTBT: 7-chlorotetrazolo [5,1-c]benzo[1,2,4]triazine; $\mathbf{1}$ : tetrazolo $[5,1$-c] $]$ benzo[1,2,4]triazine; 2: 7-methyltetrazolo [5,1-c]benzo[1,2,4]triazine; 3 : $[1,2,4]$ triazolo $[3,4, c]$ benzo[1,2,4]triazine; 4: 7-chloro[1,2,4]triazolo $[3,4, c]$ benzo[1,2,4]triazine; 5: 1-bromo[1,2,4]triazolo $[3,4, c]$ benzo[1,2,4]triazine. 
of growth by this drug was observed under strictly anaerobic conditions.

Antifungal activity of CTBT was higher on media containing glycerol plus ethanol instead of glucose indicating that developed functional mitochondria might be involved in drug action. This implies that apart from superoxide anion radical $\left(\mathrm{O}_{2}{ }^{-}\right)$and ROS generation CTBT does not have other direct cytotoxic effects. ROS affect many cellular functions by damaging nucleic acids, oxidizing proteins and causing lipid peroxidation [35,36]. Dismutation of superoxide into hydrogen peroxide and molecular oxygen is catalyzed by two superoxide dismutases: the $\mathrm{Cu}, \mathrm{Zn}$-depending Sod1p localized in the cytosol and the mitochondrial intermembrane space and the Mn-depending Sod2p which is localized in the mitochondrial matrix [37]. Among the gene deletion strains selected for increased CTBT sensitivity (Additional file 1 ), the $\operatorname{sod} 1 \Delta$ and $\operatorname{sod} 2 \Delta$ mutant strains were found to be the most sensitive. Additionally, the mutants deleted for SOD1 and CCS1, a copper chaperone essential for Sod1p maturation, had a similar phenotype. CTBT could act as an inhibitor of Sods. Since the $\operatorname{sod} 1 \Delta \operatorname{sod} 2 \Delta$ double mutant cells were also sensitive to CTBT the Sod1p and Sod2p superoxide dismutases cannot be the primary targets of CTBT action. Therefore, CTBT is a producer of superoxide in presence of oxygen.

CTBT could either directly be a reducing agent or, alternatively, as a cofactor in the context of an enzyme. Our genetic data suggest that CTBT is not acting via a single enzyme because such deletion mutants would be resistant to CTBT and could be easily isolated by genetic means. In fact, in similar screen we were unable to find deletion mutants resistant to CTBT used at the concentration of $10 \mu \mathrm{g} / \mathrm{ml}$. However, the possibility of a redundant enzymatic activity exists plus the requirement of reducing equivalents. In intact cells, the superoxide anion radical $\left(\mathrm{O}_{2}{ }^{-}\right)$is the precursor of most ROS and is generated under specific bioenergetic conditions at several sites within the mitochondrial electron-transport system. Most of superoxide is converted to $\mathrm{H}_{2} \mathrm{O}_{2}$ and oxygen inside and outside the mitochondrial matrix by superoxide dismutases [36,38]. Non-mitochondrial sources of ROS involve cytochrome $b_{5}$ reductase, NADPH oxidases, lipoxygenases, monoamine oxidases, xanthine oxidase and others [36,37]. In S. cerevisiae, the main sites of mitochondrial superoxide formation are one NADH:ubiquinone oxidoreductase located in the inner mitochondrial membrane and facing the matrix [39], two NADH:ubiquinone oxidoreductases facing the mitochondrial intermembrane space and the ubiquinol: cytochrome $c$ reductase [40]. This is in line with our scheme proposing CTBT induced superoxide generation in mitochondria (Figure 7). Furthermore, paraquat, the herbicide generating superoxide by redox cycling, is principally reduced by mitochondrial NADH dehydrogenases [41].

Most identified genes required for increased CTBT susceptibility were found to be involved in mitochondrial biogenesis and function, DNA repair, gene expression, lipid metabolism and stress response (Table 1). Many of them are known to be involved in defense processes protecting yeast cells against oxidative stress $[35,37]$ and have been previously identified in genomewide analyzes of yeast deletion mutant strains sensitive to oxidative stress induced by a superoxide generator menadione, hydrogen peroxide, organic peroxides [20-22], arsenite and cadmium [23].

Remarkable is a high frequency of CTBT hypersensitive deletion mutants with affected mitochondrial functions. A requirement of energy for the repair of oxidatively damaged molecules has previously been proposed to explain why petite mutants are more sensitive to oxidative stress than wild type strains [42]. On the other hand one cannot rule out a higher permeability of mitochondrial membranes for CTBT, superoxide or other ROS generated in dysfunctional mitochondria. The increased damage to mutant mitochondria caused by ROS may also reduce the mitochondrial membrane potential under critical level resulting in the arrest of mitochondrial biogenesis required for growth of eukaryotic cells [43].

Other significant pathways involved in CTBT susceptibility were also identified by the presence of several genes involved in the same pathway or encoding the subunits of the particular cellular complexes. This concerns genes involved in the RAD52 and RAD6 epistasis groups of DNA repair, Paf1 complex of RNA polymerase II (CDC73, HPR1 and RTF1), protein sorting to vacuole (VPS15, VPS34), vacuolar ATPase (TFP1, TFP3, VMA4, VMA21, VMA22), N-terminal acetyltransferases (ARD1, NAT1, NAT3) acetylating many proteins involved in cell cycle, heat shock resistance, mating, sporulation and telomere silencing as well as genes involved in ergosterol metabolism (DAP1, ERG2, ERG3, ERG6 and ERG24) and tryptophan biosynthesis (TRP2, TRP3 and TRP5). Along with tryptophan, interruption of the synthesis of cystein, isoleucin and proline also enhanced the CTBT toxicity. The sensitivity displayed by corresponding mutant strains is apparently not the result of the absence of the amino acids because CTBT was toxic on YPD plates that contain all necessary amino acids. It is possible that the accumulation of intermediates enhances the effect of CTBT.

The overlay of expression data with phenotypic data pointed mainly to superoxide dismutase activity (Sod1, Sod2, Ccs1) and second to the activation of transcription factors Yap1, Cin5/Yap4, and Yap7. Yap1p is a 


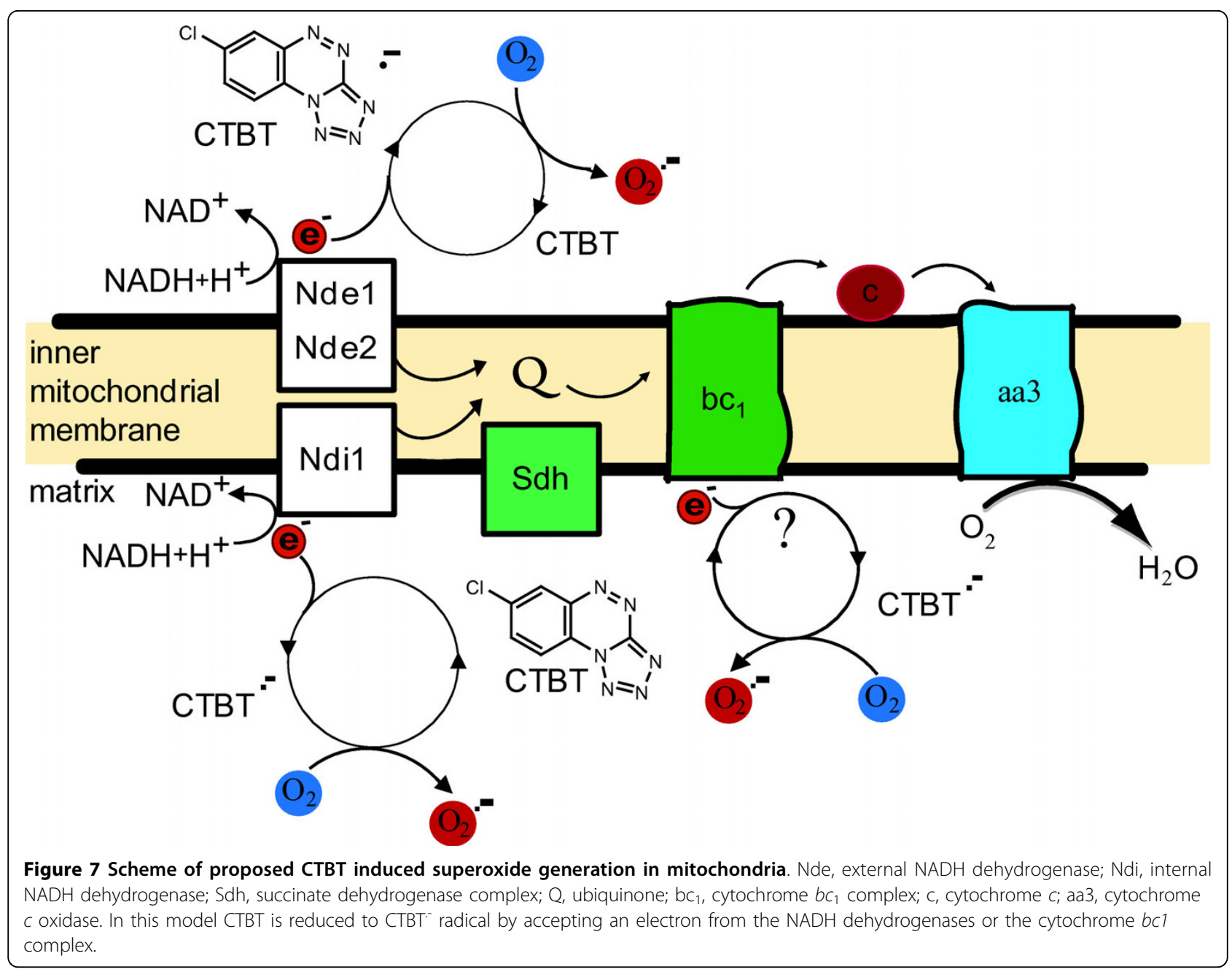

transcription activator involved in the control of multidrug resistance and oxidative stress response [44]. Reactive oxygen species (ROS) generated both from endogenous and exogenous sources induce accumulation of Yap1p in the nucleus resulting in enhanced transcription of many genes involved in removing or detoxifying ROS. Cin5/Yap4 is activated by oxidative stress [45] like Yap1. The contribution of Yap7 to transcription is less understood. Yap7 is involved in transcriptional activation of the SOD1, SOD 2 and CCS1 genes (http://yeastract.com;[27]). However, we found no transcriptional induction of DNA damage specific genes and possibly because this stress type does not surface within the observed time frame. These findings suggest a highly focused primary effect of CTBT on oxidative stress and delayed effects on other pathways.

CTBT enhances activity of several drugs [2]. This synergy becomes perhaps clearer when considering the production of superoxide and other ROS. Our phenotypic screen showed an enhanced sensitivity of mutants in the RAD52 and RAD6 epistasis groups of DNA repair. 5 -Fluorocytosine is a drug which enters nucleotide metabolism and damages the cells by interfering with dNTP and mRNA synthesis. CTBT could act at two levels. Oxidative damage might cause DNA damage and at the same time hamper deoxynucleotide synthesis requiring glutathione or thioredoxin for production via ribonucleotide reductase. Azoles and terbinafin both target ergosterol synthesis. Interestingly, CTBT reduces transcription of most genes for the enzymes of the pathway. Finally, CTBT might exacerbate cycloheximide inhibition on translation by reduction of synthesis of ribosomal protein genes. Oxidative stress causes inactivation of the target of rapamycin complex 1 (TORC1) and thus inactivation of the Sfp1, one major activator of transcription of ribosomal protein genes. An interaction with the popular echinocandines remains to be shown. Up to now the combination of antifungals has been tried in vitro in many different combinations. The application of combinations may reduce costs, and 
importantly shift the effect of the drug towards fungicidal activity (for review see [17]). Apart from combinations of classical antifungals (amphotericin B, azoles, echinocandines), unusual combinations lead to unexpected results as for example in the case of azoles plus calcineurin inhibitors [46] or with membrane active compounds [47].

\section{Conclusions}

CTBT, apart from its weak antifungal activity, is able to strongly inhibit the proliferation of multidrug resistant yeast cells in combination with subinhibitory concentrations of other antifungals. Its mode of action depending on the molecular oxygen has been resolved using the combination of two genome-wide approaches including the screening of yeast deletion library for CTBT hypersensitivity mutants and transcriptome analysis of yeast cells exposed to this drug. We found that CTBT induces an increased production of superoxide and oxidative stress associated with damage to mitochondria and genomic DNA. Yeast cells deleted in nonessential genes encoding proteins involved mainly in mitochondrial function, DNA repair, transcription and oxidative stress response are hypersensitive to $\mathrm{CTBT}$. CTBT rapidly induces transcription of oxidant and stress response defense genes activated mainly by Yap1 and Yap4/Cin5 transcription factors.

The exact molecular mechanism of CTBT action, associated with superoxide generation in mitochondria, is not known so far. It does not require a complete and functional respiratory chain as demonstrated by CTBT sensitivity of $r h o^{-}$mutant cells. Theoretical treatment of CTBT activity revealed that this compound might be amenable to one electron reduction. Electrons donated from mitochondrial NADH dehydrogenases or cytochrome $b c_{1}$ complex can lead to CTBT anion radical formation that can be re-oxidized by molecular oxygen generating superoxide probable on the both sides of the inner mitochondrial membrane (Figure 7). Our combined genome wide approaches show the power of yeast genetics and transcript profiling to define mode of functioning of bioactive substances.

\section{Methods}

\section{Strains and culture conditions}

The following yeast strains were used:S. cerevisiae strains FY1679-28C (MATa ura3-52 trp1-63 leu2-1

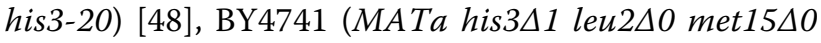

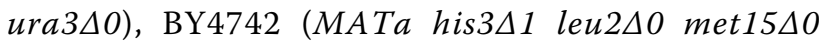
ura $3 \triangle 0$ ), the complete set of deletion mutants derived from the haploid strain BY4741 (EUROSCARF, http:// web.uni-frankfurt.de/fb15/mikro/euroscarf), EG103

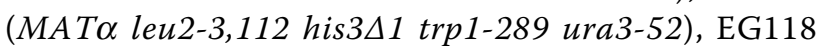
(EC103 with $\operatorname{sod} 1 \triangle A:: U R A 3)$, EG110 (EC103 with sod2::
TRP1), EG133 (EC103 with sod1 $A$ A::URA3 sod2::TRP1) [49]. A plasmid expressing an N-terminal GFP-Yap1 fusion was obtained from M. Toledano [50]. Cells were grown in YPD medium containing $2 \%(\mathrm{w} / \mathrm{v})$ glucose, $1 \%$ $(\mathrm{w} / \mathrm{v})$ yeast extract, $2 \%(\mathrm{w} / \mathrm{v})$ peptone, in YPGal medium (as YPD but $2 \%(\mathrm{w} / \mathrm{v})$ galactose instead of $2 \%$ glucose), in YNB medium containing $2 \%(\mathrm{w} / \mathrm{v})$ glucose $0.67 \%$ yeast nitrogen base without amino acids (Difco), in YPGE medium (as YPD but $2 \%$ glycerol plus $2 \%$ ethanol instead of $2 \%$ glucose). The media were solidified with $2 \%(\mathrm{w} / \mathrm{v})$ bacto agar. Where appropriate, amino acids, uracil, ergosterol $(20 \mu \mathrm{g} / \mathrm{ml})$, Tween $80(0.06 \%$, w/v) or G418 sulphate $(200 \mu \mathrm{g} / \mathrm{ml})$ was added. For induction of $r h o^{-} / r h o^{0}$ mutants, cells were grown in YPD containing of ethidium bromide $(25 \mu \mathrm{g} / \mathrm{ml})$ or CTBT for $24 \mathrm{~h}$, diluted and plated onto solid YPD. Frequency of respiration deficient mutants in yeast culture was determined after staining colonies with TTC (triphenyltetrazolium chloride) or replica plating onto YPGE plates.

\section{Drug susceptibility testing}

Susceptibility of yeast cells to CTBT was determined using the spot test assay. Aliquots of yeast cultures were spotted onto YPD plates containing the indicated concentrations of CTBT. Plates were incubated at $30^{\circ} \mathrm{C}$ for 6 days. In liquid media, susceptibilities to CTBT were assayed by the broth microdilution method in 96 well plate containing $200 \mu \mathrm{l}$ YPD supplemented with different concentrations of CTBT. The growth at $30^{\circ} \mathrm{C}$ was scored after 24 and $48 \mathrm{~h}$. Susceptibility to CTBT was also assessed using zone inhibition assays. Approximately $10^{7}$ cells were plated onto YPD media, the filter discs (diameter of $6 \mathrm{~mm}$ ) soaked with indicated amounts of CTBT were placed on the plates which were incubated at $30^{\circ} \mathrm{C}$ for 3-6 days before determination of the diameter of the zone of growth inhibition.

\section{Screening for altered CTBT susceptibility}

The collection of viable gene deletion mutants in the BY4741 background was screened for both CTBT hypersensitive and CTBT resistant strains. EUROSCARF mutant strains were transferred from 96 well master plates to solid YPD media supplemented with G418 sulphate. After 3 days, cells from grown colonies were inoculated into the corresponding wells of a 96 well microtiter plates containing $200 \mu \mathrm{l}$ YPD supplemented with G418 sulphate. Cells were cultured $24 \mathrm{~h}$ at $30^{\circ} \mathrm{C}$, diluted 20-times in YPD medium containing G418 sulphate and replica pinned onto YPD control plates and plates containing different concentration of CTBT (2 and $4 \mu \mathrm{g} / \mathrm{ml}$ ) using a 96 floating pin replicator. The mutant strains were arranged in quadruplet to create a dilution in a given square giving a total of 96 strains plated per agar plate. The plates were incubated at $30^{\circ} \mathrm{C}$ 
and scored after 3 and 6 days. The altered sensitivity of strains to CTBT was assessed visually from the growth on the test medium relative to the growth on YPD control plate. To pin-point cellular functions that confer altered CTBT susceptibility, we searched for functional categories in the sensitive gene set according to FunCat at MIPS http://mips.gsf.de. Gene ontology (GO) analysis was done using GO Term Finder in SGD http://yeastgenome.org.

\section{Microarray analysis}

Wild type BY4741 cells were grown for 4 generations in YPD at $30^{\circ} \mathrm{C}$ to $\mathrm{OD}_{600}$ of 1 before CTBT solution (2 $\mathrm{mg} / \mathrm{ml}$ ) was added to a final concentration of $2 \mu \mathrm{g} / \mathrm{ml}$. After 5, 10, 20 and 40 minutes cells were harvested, washed in ice-cold water and immediately frozen. RNA was isolated by the hot phenol method. $20 \mu \mathrm{g}$ of total RNA was used for direct labeling cDNA synthesis with either Cy3-dCTP or Cy5-dCTP. Labeled cDNAs were purified with GFX columns (GE Healthcare). Hybridization to cDNA microarrays (Ontario Cancer Institute, Toronto, Canada) was done in triplicates with color inversion in $60 \mu \mathrm{l}$ DigEasyHyb solution (Roche, Mannheim, Germany) overnight at $37^{\circ} \mathrm{C}$. After hybridization, microarrays were washed three times in $1 \times \mathrm{SSC}$, and $0.1 \% \mathrm{SDS}$ at $50^{\circ} \mathrm{C}$ for $10 \mathrm{~min}$, followed by $1 \mathrm{~min}$ in $1 \times \mathrm{SSC}$ und $0.1 \times \mathrm{SSC}$ at room temperature and 5 min $500 \mathrm{rpm}$ spin to dryness. Microarrays were analyzed on an Axon 4000B scanner (Invitrogen, Molecular Devices) with Gene Pix Pro 4.1 (Axon; Molecular Probes).

For individual microarrays the intensity of the two fluorescent channels were normalized to the mean of ratio of medians of all unflagged features using the Genepix Pro 4.1 normalization option. Values of not found features were excluded from further analysis. Genes labeled as dubious ORFs in SGD were also removed from analysis. Mean ratios were calculated for features with at least 4 values. The filtered normalized values used for further analysis are available as supplementary file. Cluster analysis [51,52]http://bonsai.ims.u-tokyo.ac. $\mathrm{jp} / \sim$ mdehoon/software/cluster/software.htm was performed using the cluster 3 and visualized with TreeView [53]http://jtreeview.sourceforge.net. Significant associations to either GO-terms or transcription factors were obtained by GO-Term Finder at SGD http://www.yeastgenome.org and T-Profiler http://www.t-profiler.org [28]. TreeView files corresponding to the figures are supplied as Additional files 3, 4, 5, 6, 7, 8. Values of genes associated with the most significant terms were visualized by Cluster analysis using complete linkage and correlation as similarity metric. GO assignments were graphically included in the cluster analysis by setting their column weight value to zero. Microarray data have been deposited at ArrayExpress http://www. ebi.ac.uk/microarray with the accession E-MEXP-2307.

\section{Fluorescence microscopy and spectrometry}

Intracellular ROS production was examined using MitoSOX Red (Molecular Probes). MitoSOX Red is a lipid soluble cation that accumulates in the mitochondrial matrix where it can be oxidized to a fluorescent product by superoxide [31]. Yeast strains from initial concentration of $2 \times 10^{6}$ cells $/ \mathrm{ml}$ were grown in YPGal medium containing indicated concentration of CTBT. After $12 \mathrm{~h}$ of growth aliquots of $10^{9}$ cells were washed twice with phosphate-buffered saline (PBS) and incubated in the dark for $20 \mathrm{~min}$ in $5 \mu \mathrm{M}$ MitoSOX Red. Cells were washed three times with PBS, resuspended in PBS and the percentage of cells positively stained with MitoSOX Red was determined by fluorescence microscopy using a Zeiss Axioplan 2 fluorescence microscope (Thornwood, NY). Images were recorded on fluorescence microscope with a Spot Pursuit camera (Visitron Systems, Puchheim, Germany). Fluorescence of cells was also determined using fluorescence spectrometer (Jasco FP-6300, Tokyo) with excitation and emission wavelengths of 510 and $580 \mathrm{~nm}$, respectively. Nuclei were stained by addition of $1 \mu \mathrm{l} / \mathrm{ml}$ Hoechst 33342 (Molecular Probes). GFP was visualized in live cells approximately 5 minutes after treatment with CTBT without fixation using excitation and emission wavelengths of 355 and $465 \mathrm{~nm}$, respectively.

\section{Quantum chemical calculations}

The usual computational protocol for quantum chemical calculations was used. The optimal geometries of the molecules were obtained by complete geometry optimization employing the AM1 method. This geometry was used as input for the single SCF calculations by the ab Initio method (minimal STO-3G basis set) to obtain the energies and wave functions [54].

\footnotetext{
Additional file 1: CTBT sensitive mutant strains. A pdf file containing

all identified CTBT hypersensitive gene deletion mutants.

Click here for file

[http://www.biomedcentral.com/content/supplementary/1471-2164-11153-S1.PDF ]

Additional file 2: Clustered CTBT induced genes. Contains the graphics of the clustered transcript profile results from 500 significantly induced or repressed genes.

Click here for file

[http://www.biomedcentral.com/content/supplementary/1471-2164-11153-S2.PDF ]

Additional file 3: Cluster data for figure S1. Contains the text information to reconstruct figure $\mathrm{S} 1$ with TreeView.

Click here for file

[http://www.biomedcentral.com/content/supplementary/1471-2164-11153-S3.CDT ]
} 
Additional file 4: Cluster data for figure $2 \mathrm{~A}$ containing genes associated to the GO-term stress response. Contains the text information to reconstruct figure 2A with TreeView.

Click here for file

[http://www.biomedcentral.com/content/supplementary/1471-2164-11153-S4.CDT]

Additional file 5: Cluster data for figure 2B containing genes regulated and targeted by Yap1 and Cin5. Contains the text information to reconstruct figure $2 \mathrm{~B}$ with TreeView.

Click here for file

[http://www.biomedcentral.com/content/supplementary/1471-2164-11153-S5.CDT]

Additional file 6: Cluster data for figure $2 \mathrm{C}$ containing genes associated to the GO-term lipid biosynthetic process. Contains the text information to reconstruct figure $2 \mathrm{C}$ with TreeView.

Click here for file

[http://www.biomedcentral.com/content/supplementary/1471-2164-11153-S6.CDT]

Additional file 7: Cluster data for figure 3A showing enriched GOterms in 169 genes required for CTBT resistance. Contains the text information to reconstruct figure 3A with TreeView.

Click here for file

[http://www.biomedcentral.com/content/supplementary/1471-2164-11153-S7.CDT ]

Additional file 8: Cluster data for figure 3B comparing CTBT sensitive strains to hydrogen peroxide, menadion, mefloquine and ibuprophen sensitive strains. Contains the text information to reconstruct figure $3 \mathrm{~B}$ with TreeView.

Click here for file

[http://www.biomedcentral.com/content/supplementary/1471-2164-11153-S8.CDT ]

\section{Abbreviations}

cDNA: complementary DNA; CTBT: 7-chlorotetrazolo [5,1-c]benzo[1,2,4] triazine; DAPI: 4',6-diamidino-2-phenylindole; GFP: green fluorescent protein; GO: gene ontology; HOMO: highest occupied orbital; LUMO: lowest unoccupied orbital; mtDNA: mitochondrial DNA; NADH(P): nicotinamide adenine dinucleotide (phosphate); ORF: open reading frame; PBS: phosphate buffered saline; ROS: reactive oxygen species; SDS: sodium dodecyl sulfate; SGD: Saccharomyces genome database; SSC: saline-sodium citrate buffer.

\section{Acknowledgements}

We thank P. Griac for help with mutant screening, E. Gralla for strains, M. Toledano for material. The contribution of the Vienna FH-Biotech students to microarray analysis is acknowledged. We thank Gy. Hajos for providing the benzotriazine derivatives. MB was supported by grants from Comenius University (Grant UK 286/09) and FEMS (Research Fellowship FRF 2009-1). VK and $\mathrm{IH}$ were supported by grant from the Slovak Research and Developmental Agency (WCE-0064-07-01). CS was supported by the Austrian Science Fund (FWF) grant B12-P19966, the UNICELLSYS FP7 grant (to Gustav Ammerer) and the Herzfelder Foundation. JG was supported by FWF grants P20444, P18955 and F34. JS was supported by grants from the Slovak Research and Developmental Agency (LPP-0022-06, LPP-0011-07, WCE-0064-07-04) and Slovak Grant Agency of Science (VEGA 1/0001/09).

\section{Author details}

${ }^{1}$ Comenius University in Bratislava, Department of Microbiology and Virology, 84215 Bratislava, Slovak Republic. ${ }^{2}$ Slovak Academy of Sciences, Institute of Animal Genetics and Biochemistry, 90028 Ivanka pri Dunaji, Slovak Republic. ${ }^{3}$ University of Vienna, Max F Perutz Laboratories, Department of Chromosome Biology, A-1030 Vienna, Austria. ${ }^{4}$ Comenius University in Bratislava, Department of Organic Chemistry, 51215 Bratislava, Slovak Republic. ${ }^{5}$ University of Vienna, Max F Perutz Laboratories, Department of Biochemistry and Cell Biology, A-1030 Vienna, Austria.

\section{Authors' contributions}

$M B, V B, Z O$ and $I H$ participated on the screening of the yeast deletion library. MB and JG carried out the fluorescence microscopy and spectrometry. MB prepared RNA and CS performed the transcriptome analysis, data analysis and graphical presentation. PZ carried out the quantum chemical calculations. JS conceived of the study, participated in its design, analyzed data and with CS prepared the last version of the manuscript. All authors read and approved the final manuscript.

Received: 23 October 2009

Accepted: 4 March 2010 Published: 4 March 2010

\section{References}

1. Nucci M, Marr KA: Emerging fungal diseases. Clin Infect Dis 2005, 41:521-526.

2. Cernicka J, Kozovska Z, Hnatova M, Valachovic M, Hapala I, Riedl Z, Hajós G, Subik J: Chemosensitisation of drug-resistant and drug-sensitive yeast cells to antifungals. Int J Antimicrob Agents 2007, 29:170-178.

3. Anderson JB: Evolution of antifungal-drug resistance: mechanisms and pathogen fitness. Nat Rev Microbiol 2005, 3:547-556.

4. Ghannoum MA, Rice LB: Antifungal agents: mode of action, mechanisms of resistance, and correlation of these mechanisms with bacterial resistance. Clin Microbiol Rev 1999, 12:501-517.

5. Lee RE, Liu TT, Barker KS, Lee RE, Rogers PD: Genome-wide expression profiling of the response to ciclopiroxolamine in Candida albicans. $J$ Antimicrob Chemother 2005, 55:655-662.

6. Vazquez JA, Sobel JD: Anidulafungin: a novel echinocandin. Clin Infect Dis 2006, 43:215-222.

7. Prasad R, Panwar SL, Smriti A: Drug resistance in yeast - an emerging scenario. Adv Microb Physiol 2002, 46:155-201.

8. Sanglard D: Resistance of human fungal pathogens to antifungal drugs. Curr Opin Microbiol 2002, 5:379-385.

9. Maesaki S, Marichal P, Hossain MA, Sanglard D, Bossche Vanden H, Kohno S: Synergic effects of tacrolimus and azole antifungal agents against azoleresistant Candida albicans strains. J Antimicrob Chemother 1998, 42:747-753.

10. Egner $R$, Bauer $B E$, Kuchler $K$ : The transmembrane domain 10 of the yeast Pdr5p ABC antifungal efflux pump determines both substrate specificity and inhibitor susceptibility. Mol Microbiol 2000, 35:1255-1263.

11. Marchetti O, Moreillon P, Glauser MP, Bille J, Sanglard D: Potent synergism of the combination of fluconazole and cyclosporine in Candida albicans. Antimicrob Agents Chemother 2000, 44:2373-2381.

12. Edlind T, Smith L, Henry K, Katiyar S, Nickels J: Antifungal activity in Saccharomyces cerevisiae is modulated by calcium signaling. Mol Microbiol 2002, 46:257-268.

13. Kralli A, Yamamoto KR: An FK506-sensitive transporter selectively decreases intracellular levels and potency of steroid hormones. J Biol Chem 1996, 271:17152-17156.

14. Onishi J, Meinz M, Thompson J, Curotto J, Dreikorn S, Rosenbach M, Douglas C, Abruzzo G, Flattery A, Kong L, Cabello A, Vicente F, Pelaez F, Diez MT, Martin I, Bills G, Giacobbe R, Dombrowski A, Schwartz R, Morris S, Harris G, Tsipouras A, Wilson K, Kurtz MB: Discovery of novel antifungal (1,3)-beta-G-glucan synthase inhibitors. Antimicrob Agents Chemother 2000, 44:368-377.

15. Paulsen IT, Lewis K: Microbial multidrug efflux Norfolk, UK: Horizon Scientific Press 2002.

16. Di Pietro A, Conseil G, Pérez-Victoria JM, Dayan G, Baubichon-Cortay H, Trompier D, Steinfels E, Jault JM, de Wet H, Maitrejean M, Comte G, Boumendjel A, Mariotte AM, Dumontet C, McIntosh DB, Goffeau A, Castanys S, Gamarro F, Barron D: Modulation by flavonoids of cell multidrug resistance mediated by P-glycoprotein and related $A B C$ transporters. Cell Mol Life Sci 2002, 59:307-322.

17. Vazquez JA: Clinical practice: combination antifungal therapy for mold infections: much ado about nothing?. Clin Infect Dis 2008, 46:1889-1901.

18. Balzi E, Chen W, Ulaszewski S, Capieaux E, Goffeau A: The multidrug resistance gene PDR1 from Saccharomyces cerevisiae. J Biol Chem 1987, 262:16871-16879. 
19. Delaveau T, Delahodde A, Carvajal E, Subik J, Jacq C: PDR3, a new yeast regulatory gene, is homologous to $P D R 1$ and controls the multidrug resistance phenomenon. Mol Gen Genet 1994, 244:501-511.

20. Higgins VJ, Alic N, Thorpe GW, Breitenbach M, Larsson V: Phenotypic analysis of gene deletant strains for sensitivity to oxidative stress. Yeast 2002, 19:203-214.

21. Thorpe GW, Fong CS, Alic N, Higgins VJ, Dawes IW: Cells have distinct mechanisms to maintain protection against different reactive oxygen species: oxidative-stress-response genes. Proc Natl Acad Sci USA 2004, 101:6564-6569.

22. Tucker $\mathrm{CL}$, Fields S: Quantitative genome-wide analysis of yeast deletion strain sensitivities to oxidative and chemical stress. Comp Funct Genom 2004, 5:216-224.

23. Thorsen M, Perrone GG, Kristiansson E, Traini M, Ye T, Dawes IW, Nerman O, Tamás MJ: Genetic basis of arsenite and cadmium tolerance in Saccharomyces cerevisiae. BMC Genomics 2009, 10:105, p. 1-15..

24. Gasch AP, Spellman PT, Kao CM, Carmel-Harel O, Eisen MB, Storz G, Botstein D, Brown PO: Genomic expression programs in the response of yeast cells to environmental changes. Mol Biol Cell 2000, 11:4241-4257.

25. Marion RM, Regev A, Segal E, Barash Y, Koller D, Friedman N, O'Shea EK: Sfp1 is a stress- and nutrient-sensitive regulator of ribosomal protein gene expression. Proc Natl Acad Sci USA 2004, 101:14315-14322.

26. Hosiner D, Lempiäinen $H$, Reiter W, Urban J, Loewith R, Ammerer G, Shore D, Schüller C: Arsenic toxicity to Saccharomyces cerevisiae is a consequence of inhibition of the TORC1 kinase combined with a chronic stress response. Mol Biol Cell 2009, 20:1048-1057.

27. Harbison CT, Gordon DB, Lee TI, Rinaldi NJ, Macisaac KD, Danford TW, Hannett NM, Tagne JB, Reynolds DB, Yoo J, Jennings EG, Zeitlinger J, Pokholok DK, Kellis M, Rolfe PA, Takusagawa KT, Lander ES, Gifford DK, Fraenkel E, Young RA: Transcriptional regulatory code of a eukaryotic genome. Nature 2004, 431:99-104.

28. Boorsma A, Foat BC, Vis D, Klis F, Bussemaker HJ: T-profiler: scoring the activity of predefined groups of genes using gene expression data. Nucleic Acids Res 2005, 33:W592-595.

29. Schüller C, Mamnun YM, Mollapour M, Krapf G, Schuster M, Bauer BE, Piper PW, Kuchler K: Global phenotypic analysis and transcriptional profiling defines the weak acid stress response regulon in Saccharomyces cerevisiae. Mol Biol Cell 2004, 15:706-720.

30. Kuge $\mathrm{S}$, Jones $\mathrm{N}$, Nomoto A: Regulation of yAP-1 nuclear localization in response to oxidative stress. EMBO J 1997, 16:1710-1720.

31. Johnson-Cadwell LI, Jekabsons MB, Wang A, Polster BM, Nicholls DG: Mild uncoupling does not decrease mitochondrial superoxide levels in cultured cerebellar granule neurons but decreases spare respiratory capacity and increases toxicity to glutamate and oxidative stress. $J$ Neurochem 2007, 101:1619-1631.

32. Solans A, Zambrano A, Rodríguez M, Barrientos A: Cytotoxicity of a mutant huntingtin fragment in yeast involves early alterations in mitochondrial OXPHOS complexes II and III. Hum Mol Genet 2006, 20:3036-3081.

33. Harris N, Bachler M, Costa V, Mollapour M, Moradas-Ferreira P, Piper PW: Overexpressed Sod1 $p$ acts either to reduce or to increase the lifespans and stress resistance of yeast, depending on whether it is $\mathrm{Cu}(2$ +)-deficient or an active Cu, Zn-superoxide dismutase. Aging Cell 2005, 4:41-52.

34. Neklesa TK, Dawis RW: Superoxide anions regulate TORC1 and its ability to bind Fpr1:rapamycin complex. Proc Natl Acad Sci USA 2008, 105:15166-15171.

35. Temple MD, Perrone GG, Dawes IW: Complex cellular responses to reactive oxygen species. Trends Cell Biol 2005, 15:319-326.

36. Herrero E, Ros J, Belli G, Cabiscol E: Redox control and oxidative stress in yeast cells. Biochim Biophys Acta 2008, 1780:1217-1235

37. Toledano MB, Delaunay A, Biteau B, Spector D, Azevedo D: Oxidative stress response in yeast. Topics in Current genetics: Yeast Stress Responses Berlin: Springer VerlagHohmann S, Mager PWH 2003.

38. Stowe DF, Camara AKS: Mitochondrial reactive oxygen species produced in excitable cells: modulators of mitochondrial and cell function. Antioxidants \& Redox Signaling 2009, 11:1373-1414.

39. Marres CA, de Vries S, Grivell LA: Isolation and inactivation of the nuclear gene encoding the rotenone-insensitive internal NADH: ubiquinone oxidoreductase of mitochondria from Saccharomyces cerevisiae. Eur $J$ Biochem 1991, 195:857-862.
40. Fang J, Beattie DS: External alternative NADH dehydrogenase of Saccharomyces cerevisiae: a potential source of superoxide. Free Radic Biol Med 2003, 34:478-488.

41. Cocheme HM, Murphy MP: Complex lis the major site of mitochondrial superoxide production by paraquat. J Biol Chem 2008, 283:1786-1798.

42. Grant CM, Maclver FH, Dawe IW: Mitochondrial function is required for resistance to oxidative stress in the yeast Saccharomyces cerevisiae. FEBS Lett 1997, 410:219-222.

43. Gbelska Y, Subik J, Svoboda A, Goffeau A, Kovac L: Intramitochondrial ATP and cell functions: yeast cells depleted of intramitochondrial ATP lose the ability to grow and multiply. Eur J Biochem 1983, 130:281-286.

44. Moye-Rowley WS: Transcription factors regulating the response to oxidative stress in yeast. Antioxid Redox Signal 2002, 4:123-140.

45. Sollner S, Schober M, Wagner A, Prem A, Lorkova L, Palfey BA, Groll M, Macheroux P: Quinone reductase acts as a redox switch of the $20 \mathrm{~S}$ yeast proteasome. EMBO Rep 2009, 10:65-70.

46. Onyewu C, Blankenship JR, Del Poeta M, Heitman J: Ergosterol biosynthesis inhibitors become fungicidal when combined with calcineurin inhibitors against Candida albicans, Candida glabrata, and Candida krusei. Antimicrob Agents Chemother 2003, 47:956-964.

47. Afeltra J, Vitale RG, Mouton JW, Verweij PE: Potent synergistic in vitro interaction between nonantimicrobial membrane-active compounds and itraconazole against clinical isolates of Aspergillus fumigatus resistant to itraconazole. Antimicrob Agents Chemother 2004, 48:1335-1343.

48. Nourani A, Papajova D, Delahodde A, Jacq C, Subik J: Clustered amino acid substitutions in the yeast transcription regulator $\mathrm{Pdr} 3 p$ increase pleiotropic drug resistance and identify a new central regulatory domain. Mol Gen Genet 1997, 256:397-405.

49. Longo VD, Gralla EB, Valentine JS: Superoxide dismutase activity is essential for stationary phase survival in Saccharomyces cerevisiae. Mitochondrial production of toxic oxygen species in vivo. J Biol Chem 1996, 271:12275-12280

50. Delaunay $A$, Isnard $A D$, Toledano $M B: \mathrm{H}_{2} \mathrm{O}_{2}$ sensing through oxidation of the Yap1 transcription factor. EMBO J 2000, 19:5157-5166.

51. Eisen MB, Spellman PT, Brown PO, Botstein D: Cluster analysis and display of genome-wide expression patterns. Proc Natl Acad Sci USA 1998, 95:14863-14868

52. Nadon R, Shoemaker J: Statistical issues with microarrays: processing and analysis. Trends Genet 2002, 18:265-271.

53. Saldanha AJ: Java Treeview-extensible visualization of microarray data. Bioinformatics 2004, 20:3246-3248.

54. Cramer CJ: Essentials of Computational Chemistry: Theories and Models Chichester: J. Wiley 2002

doi:10.1186/1471-2164-11-153

Cite this article as: Batova et al:: Chemogenomic and transcriptome analysis identifies mode of action of the chemosensitizing agent CTBT (7-chlorotetrazolo[5,1-c]benzo[1,2,4]triazine). BMC Genomics 2010 11:153.

\section{Submit your next manuscript to BioMed Central and take full advantage of:}

- Convenient online submission

- Thorough peer review

- No space constraints or color figure charges

- Immediate publication on acceptance

- Inclusion in PubMed, CAS, Scopus and Google Scholar

- Research which is freely available for redistribution

Submit your manuscript at www.biomedcentral.com/submit
Biomed Central 